DOI: https://doi.org/10.47405/mjssh.v5i5.407

\begin{tabular}{|c|c|}
\hline & Malaysian Journal of Social Sciences and Humanities (MJSSH) \\
\hline Malaysian Journal of & Volume 5, Issue 5, May 2020 \\
\hline (MJ - sshrtit) & e-ISSN : 2504-8562 \\
\hline & $\begin{array}{l}\text { Journal home page: } \\
\text { www.msocialsciences.com }\end{array}$ \\
\hline
\end{tabular}

\title{
Pengaruh Kecerdasan Emosi, Kecerdasan Spiritual dan Persekitaran Keluarga Terhadap Stres Akademik Murid Sekolah Menengah
}

\author{
Andang Andaiyani Binti Ahmad1, Abdul Said Bin Ambotang1 \\ 1Fakulti Psikologi dan Pendidikan, Universiti Malaysia Sabah (UMS)
}

Correspondence: Andang Andaiyani Binti Ahmad (danish_danials720@yahoo.com)

\begin{abstract}
Abstrak
Kajian ini bertujuan untuk mengenal pasti hubungan dan pengaruh kecerdasan emosi, kecerdasan spiritual dan persekitaran keluarga terhadap stres akademik murid sekolah menengah luar bandar sekolah bahagian Tawau di Negeri Sabah. Seramai 398 orang responden dari 21 buah sekolah luar bandar bahagian Tawau Sabah telah terlibat dalam kajian ini. Data kajian diperoleh menggunakan instrument soal selidik tertutup yang mengandungi 106 item yang telah diubah suai daripada instrument yang telah dibangunkan oleh pengkaji-pengkaji terdahulu. Instrumen kecerdasan Emosi oleh Cadman dan Brewer dengan menggabungkan idea Model Mayer dan Salovey: Four Branch Model of Emotional Intelligence, Goleman dan Noriah. Instrumen kecerdasan spiritual oleh Zohar dan Marshal, instrumen persekitaran keluarga adalah Family Environment Scale Fouth Edition (FES) yang telah dibina oleh Moos dan Moos, dan untuk dimensi hubungan serta instrumen Secondary School Stressor Questionaire (3SQ) yang telah dibina oleh Muhamad Saiful Bahri Yusoff. Data kajian dianalisis menggunakan perisian Statistical Packages For Social Sciences (SPSS) dan analisis Structural Equation Modelling (SEM). Analisis deskriptif menunjukkan semua variable berada pada tahap tinggi. Ujian- $t$ dan ANOVA sehala membuktikan bahwa tidak terdapat perbezaan skor min yang signifikan bagi semua variabel berdasarkan jantina dan bangsa. Ujian Korelasi Pearson pula menunjukkan wujud hubungan signifikan Kecerdasan emosi $(r=0.489, p=0.00)$, Kecerdasan Spiritual $(r=0.480, p=0.00)$, dan Persekitaran Keluarga $(r=0.516, p=0.00)$ dengan Stres Akademik murid. Dapatan kajian menunjukkan ketiga-tiga variabel peramal memberi pengaruh yang signifikan terhadap stres akademik murid pada kadar 44 peratus. Analisis juga menunjukkan variabel peramal kajian mempunyai hubungan yang signifikan dengan variabel bersandar iaitu stres akademik pada tahap sederhana tinggi dan tinggi. Adalah dicadangakan suatu kajian lanjutan dijalankan. Kajian yang dicadangkan memfokus kepada murid di sekolah menengah di bandar. Melalui dapatan boleh dibuat perbandingan antara stres akademik murid sekolah menengah bandar dan luar bandar. Selain itu, kajian lanjutan ini perlu dilakukan di peringkat sekolah rendah dan matrikulasi agar kita dapat melihat tahap dan faktor yang mempengaruhi stres akademik murid sekolah rendah dan matrikulasi.
\end{abstract}

Kata kunci: stres akademik, kecerdasan emosi, kecerdasan spiritual, persekitaran keluarga

\section{The Influence of Emotional Intelligence, Spiritual Intelligence and Family Environment Toward Academic Stress Among Students in Outskirt Area of Tawau in Sabah}

\author{
Abstract \\ This study aimed to identify the relationship and influence of Emotional Intelligence, Spiritual
}


Intelligence and Family Environment on the Academic Stress of High School Students in outskirt area of Tawau School District in Sabah. A total of 398 respondents from 21 out schools in outskirt area of Tawau Sabah were involved in this study. The data analysis obtained using a closed-ended questionnaire contained 106 items adapted from instruments that developed by pervious researchers. For Emotional Intelligence questionaire by Cadman and Brewer (2001) that incorporating Mayer and Salovey's idea model: Four Branches of Emotional Intelligence Model, Goleman (1998) and Noriah (2005). Spiritual Intelligence instrument by Zohar and Marshal (2000), for Family Environment instrument the Fouth edition 'Future Environment Scale' (FES) developed by Moos and Moos (2002) on Relationship Dimension and for Acdemic stress the instrument was (3SQ) that built by Muhamad Saiful Bahri Yusoff, (2010). Data analysis was analyzed using PPSS (Statistical Packages For Social Sciences) software (SPSS) and Structural Equation Analysis (SEM). Descriptive analysis shows that all variables are at a high level. T-test and one-way ANOVA showed that there were no significant mean score differences by gender and race. The Pearson correlation test showed emotional intelligence $(\mathrm{r}=$ $0.489, p=0.00)$, Spiritual Intelligence $(r=0.480, p=0.00)$, and Family Environment $(r=0.516, p=$ $0.00)$ with students Academic Stress. The findings show that the three variable predictors had a significant impact on student academic stress at 44 percent. The analysis also shows that independence variable as predictors have a significant relationship with the dependent variable, namely academic stress at the medium and high levels. It is recommended that a further study be conducted. The proposed study focuses on students in urban high schools. Findings can be compared between academic stress of urban and rural high school students. In addition, this advanced study needs to be done at the primary and matriculation level so that we can look at the levels and factors that influence the academic stress of primary and secondary students.

Keywords: academic stress, emotional intelligence, spiritual intelligence, family environment

\section{Pengenalan}

Dalam era kemajuan teknologi yang semakin pesat, murid-murid sekolah khasnya dan orang awam amnya terdedah dengan gelombang kemajuan secara global dan bersifat sekularisme. Keupayaan menangani stres dengan baik dapat membantu seseorang individu memelihara keadaan harmoni dan tenteram pada dirinya sendiri dan akhirnya individu itu akan mempunyai keyakinan diri yang tinggi dalam berdepan dengan cabaran hidup atau pembelajaran di institusi pendidikan. Menurut World Health Organization, 2002 stres kini antara satu epidemik global kerana berlaku di mana sahaja dan pada bila-bila masa sahaja. Secara umumnya, stres boleh mendatangkan kesan yang negatif distress atau kesan positif eustress pada seseorang. Stres berlaku pada kanak-kanak, remaja, orang dewasa dan juga warga tua. Stres kini telah menjadi satu elemen dalam kehidupan manusia tanpa mengira umur dan bangsa (Garret, 2001), stres yang ada pada masa kini adalah sebuah atribut kehidupan moden (Kupriyanov dan Zhdanov, 2014). Stres akademik adalah hasil gabungan permintaan berkaitan dengan akademik yang melebihi sumber mudah suai yang sedia ada pada murid (Kadapatti dan Vijayalaxmi, 2012). Stres akademik adalah stres yang sering dialami oleh para pelajar sama ada yang masih berada di bangku sekolah ataupun yang telah melanjutkan pengajian ke peringkat yang lebih tinggi. Kajian ini akan melihat faktor pengaruh kecerdasan emosi, kecerdasan spiritual, persekitaran keluarga terhadap stres akademik murid luar bandar adalah sangat penting bagi kita untuk mengetahui faktor risiko dan kesan stres kepada murid, hal ini adalah kerana stres bukan sahaja memberi kesan kepada kesihatan mereka malah memberi kesan terhadap pencapaian akademik murid (Abdulghani, AlKanhal, Mahmoud, Ponnamperuma, dan Alfaris, 2011), menyebabkan masalah mental dan kegemukan (Nigatu, Bultmann, dan Reijneveld, 2015).

\section{Penyataan Masalah Kajian}

Stres akademik merupakan polemik yang semakin hangat dibincangkan dalam kalangan ibu bapa dan guru. Pelbagai faktor yang boleh menyebabkan stres akademik ini untuk berlaku. Sekiranya stres akademik ini tidak ditangani, keadaan ini akan menyebabkan murid mengalami masalah mental yang 
serius. Keadaan ini sangat membimbangkan apabila statistik yang dikeluarkan oleh Kementerian Kesihatan Malaysia berkenaan masalah kesihatan mental remaja meningkat dari $19.4 \%$ dalam tahun 2006 kepada 20.0\% dalam tahun 2011 (Kementerian Kesihatan Malaysia, 2011) dan mendapati prevalen masalah kesihatan mental dalam kalangan masyarakat Malaysia berumur 16 tahun dan ke atas ialah 29.2\% (anggaran 4.2 juta). Ini bermaksud 1 dalam 3 orang masyarakat Malaysia mengalami isu yang berkait dengan masalah mental. Kajian ini turut menunjukkan bahawa prevalen masalah kesihatan mental juga adalah paling tinggi dalam kalangan mereka yang berumur 16-19 tahun (Kementerian Kesihatan Malaysia, 2015).Berada dalam sekolah menengah merupakan satu situasi penting dalam kehidupan seseorang. Hal ini adalah kerana sekolah menengah adalah titik perubahan akademik dalam kehidupan murid (Ghatol, 2017).

Pada fasa ini, kecemerlangan akademik memainkan peranan yang penting dalam menentukan perjalanan pendidikan murid ke tahap yang lebih tinggi seterusnya ke alam pekerjaan dan masa depan (Rosa dan Preethi, 2012). Oleh sebab itu, stres akademik yang tinggi akan menyebabkan masalah psikologi seperti kemurungan dan kebimbangan melampau akan memberi impak negatif terhadap pencapaian murid di sekolah (Waghachavare, Chavan, Dhumale, dan Gore, 2013). Kajian dalam negara menunjukkan murid mempunyai simptom-simptom psiko logikal dan psikosomatik seperti gangguan kebimbangan, kemurungan, insomnia, sakit kepala dan sakit belakang dengan lebih kerap akibat stres (Tan, Goh, Muhidayah, Ooi, dan Salem, 2003). Berdasarkan kajian yang telah dijalankan berkaitan hubungan stres akademik dengan kualiti hidup murid sekolah jelas menunjukkan bahawa semakin meningkat stres akademik murid maka kualiti hidup murid akan merosot dalam semua aspek (Forouzandeh, Aslani, Mehralian, dan Drees, 2016). Oleh itu kajian lepas ini mencadangkan yang stres akademik akan kesan negatif yang ketara kepada kualiti hidup murid secara keseluruhan.

\section{Objektif Kajian}

Kajian ini berusaha mencari bukti empirikal untuk menentukan pengaruh faktor kecerdasan emosi, kecerdasan spiritual dan persekitaran keluarga terhadap stres akademik murid tingkatan empat luar bandar bahagian Tawau di negeri Sabah. Secara khusus kajian ini dilaksanakan untuk mengukur objektif utama kajian seperti berikut.

I. Menentukan hubungan faktor kecerdasan emosi, kecerdasan spiritual dan persekitaran keluarga terhadap stres akademik murid.

II. Mengenal pasti pengaruh langsung faktor kecerdasan emosi, kecerdasan spiritual dan persekitaran keluarga terhadap stres akademik murid

\section{Tinjauan Literatur}

\section{Konsep Stres Akademik}

Stres akademik merupakan hasil daripada tekanan yang dialami dalam proses menuntut ilmu. Berdasarkan dapatan kajian Essel dan Owusu, (2017) telah menyenaraikan bahawa stres akademik boleh berlaku kerana beban kerja, markah rendah, peperiksaan dan waktu belajar yang panjang. Menurut (Seligman, Walker dan Rosenhan, 2001) pula stres akademik ialah kombinasi kebimbangan kognitif, somatik, emosi dan sikap yang akan menghasilkan perasaan tidak selesa, takut ataupun bimbang. Insiden depresi dalam kalangan remaja juga berkaitan dengan keadaan tidak fokus, takut gagal, berpandangan negatif pada masa depan (Busari, 2012). Terdapat juga murid yang mengalami keletihan berlebihan sebagi respons kepada stres akademik. Lebih dari 90 peratus pelajar bersetuju menyatakan bahawa mereka mengalami stres sekali atau lebih sepanjang proses persekolahan (Shaikh et al., 2004).

\section{Konsep Kecerdasan Emosi}

Terdapat beberapa kajian lepas yang membuktikan bahawa kecerdasan emosi yang tinggi dapat mengurangkan tahap stres dan tahap depresi (Saklofske, Austin, \& Minski, 2003); (Downey, Johnston, 
Hansen, Birney dan Stough, 2010) dan (Zavala dan Lopez, 2012). Slaski dan Cartwright, (2002) Slaski dan Cartwright (2002) pula mendapati individu yang mempunyai nilai kecerdasan emosi yang tinggi mempunyai stres subjektif yang rendah, lebih sihat dan sejahtera serta mempamerkan gaya pengurusan yang lebih baik. Kajian-kajian lepas juga menunjukkan bahawa hubungan atau perkaitan antara kecerdasan emosi dengan stres. Kecerdasan emosi yang tinggi membolehkan individu mempunyai kemahiran yang baik dalam mengurus stres serta menunjukkan dan mengurus emosi mereka (Greven, Chamorro-Premuzic, Arteche dan Furnham, 2008). Kecerdasan emosi yang baik perlu ada dalam diri murid sekolah kerana stres yang wujud dalam usia remaja adalah hasil dari kesukaran dalam menangani cabaran personal dan persekitaran (Forushani dan Besharat, 2011). Dalam kajian oleh menunjukkan bahawa terdapat hubungan negatif yang sangat signifikan antara kecerdasan emosi dengan stres akademik. Hal ini bermakna semakin tinggi kecerdasan emosi maka semakin rendah stres akademik serta sebaliknya (Chlarasinta Duri Kartika, 2015).

\section{Konsep Kecerdasan Spiritual}

Pada hari ini spiritual telah dianggap sebagai salah satu dimensi kesihatan, seperti yang dicadangkan oleh Pertubuhan Kesihatan Sedunia (WHO) yang mendefinisikan kesihatan spiritual adalah satu bentuk kesihatan (Esfahani M., 2010). Dalam “International Classification of Diseases-10," WHO telah menghubungkaitkan antara dimensi kesihatan fizikal, mental dan sosial serta dimensi spiritual mempunyai hubungan dengan kesihatan seseorang individu dan keadaan ini perlu diambil kira dalam kehidupan manusia secara holistik (World Health Organization, 2009). Kecerdasan spiritual serta agama juga telah terbukti dapat berfungsi sebagai penawar dalam menangani pengaruh negatif seperti penyakit, stres dan perasaan tidak gembira (H. G. Harrison, Koenig, Hays, Eme-Akwari, dan Pargament, 2001). Menurut Abbasi, Azizi, Goshki, Rad dan Lakah, (2012) secara umum kesihatan spiritual merujuk kepada keseronokan dalam menerima takdir, emosi positif, etika dan hubungan dengan tuhan yang dinamik dan harmoni. Di samping itu kesihatan spiritual juga adalah dimensi asas dalam kesihatan dan kesejahteraan (Rahimi, 2015) dan mampu mencegah penyakit fizikal (Abbasian, Abbasi, Gooshki dan Memariani, 2016). Kecerdasan spiritual juga satu manifestasi bagi hubungan dengan tuhan (Sahraian, Gholami dan Omidvar, 2011).

Kajian lepas mencadangkan bahawa kecerdasan spiritual boleh digunakan untuk menghalang dan mengawal stres dan depresi dalam kalangan murid. Kajian oleh Mostafa Jafari, Tahereh Sharifi Ebad, Mansour Rezaei, dan Hossein Ashtarian, (2017) menunjukkan bahawa kecerdasan spiritual mampu menjadi medium dalam mengurangkan masalah depresi dalam kalangan murid. Dalam kajian oleh Amir Musarezaie, Homayoon Naji Esfahani, Tahereh Momeni-Ghaleghasemi dan Mahin Aminoroaia, (2013) menunjukkan bahawa purata depresi dan keresahan dalam kalangan murid perempuan adalah lebih tinggi berbanding murid lelaki dan depresi dan keresahan mempunyai hubungan yang signifikan dengan kecerdasan spiritual.

\section{Konsep Persekitaran Keluarga}

Beberapa kajian mengesahkan bahawa stres akademik dan persekitaran keluarga mempunyai hubungan dan pengaruh antara satu sama lain. Kajian oleh (Leung, Yeung dan Wong, 2010) mengindikasikan stres akademik sebagai faktor risiko yang mampu meningkatkan kadar keresahan dalam kalangan murid dan sokongan emosi daripada ibu bapa pula adalah faktor pelindung yang menyumbang kepada kesihatan mental murid yang lebih baik. Hubungan persekitaran keluarga yang harmoni akan membolehkan individu itu merasakan hadirnya cinta dan kepercayaan. Keadaan ini membolehkan murid untuk berasa lebih yakin untuk belajar dan mengenali persekitaran (Aspelmeier dan Kerns, 2003), keyakinan diri yang tinggi, optimis, kompetensi akademik yang baik (Fass dan Tubman, 2002).

Dalam kajian yang lebih terkini menunjukkan bahawa atmosfera persekitaran yang lebih bersifat menyokong dan merangsang sangat penting dalam menjadikan murid lebih progresif dalam akademik dan mencapai tujuan pendidikan mereka (Ghatol, 2017). Dalam kajian lain pula menyimpulkan bahawa hubungan ibu bapa dan murid juga menyebabkan murid mengalami stres akademik dalam bentuk tidak mempunyai keyakinan diri (Mulyadi, Rahardjon dan Basuki, 2016). Melihat dapatan kajian ini agak sukar untuk menafikan bahawa persekitaran keluarga mempunyai hubungan dan 
pengaruh dengan stres akademik dalam kalangan remaja atau murid sekolah menengah khususnya. Pemerhatian yang dilakukan oleh beberapa pengkaji terdahulu telah menunjukkan bahawa harapan ibu bapa dan guru menjadi sumber utama stres akademik dalam kalangan remaja (Jayanthi, Thirunavukarasu dan Rajkumar, 2014).

\section{Teori dan Model}

\section{Teori Kecerdasan Emosi Golemen (Golemen, 1995)}

Pada tahun 1995, Daniel Goleman telah memperkenalkan Model Kecerdasan Emosi Goleman yang mengambil kira unsur kecerdasan emosi dalam kejayaan individu. Model Kecerdasan Emosi ini merangkumi kecerdasan interpersonal, intrapersonal dan amalan praktikal. Model Kecerdasan Emosi Goleman mempunyai lima elemen iaitu mengenal emosi kendiri, keupayaan mengurus emosi kendiri, motivasi kendiri, mengendalikan perhubungan dengan orang lain dan mengenal emosi orang lain (empati). Menurut Goleman definisi kecerdasan emosi merupakan kemampuan untuk mengawal dan mengelolakan diri sendiri dan orang lain daripada aspek perasaan, emosi dan tingkah laku. Ia juga merupakan tindakan dan kepintaran untuk mengubahsuai sesuatu tingkah laku bersesuaian dengan masa dan keadaan (Goleman, 1998).

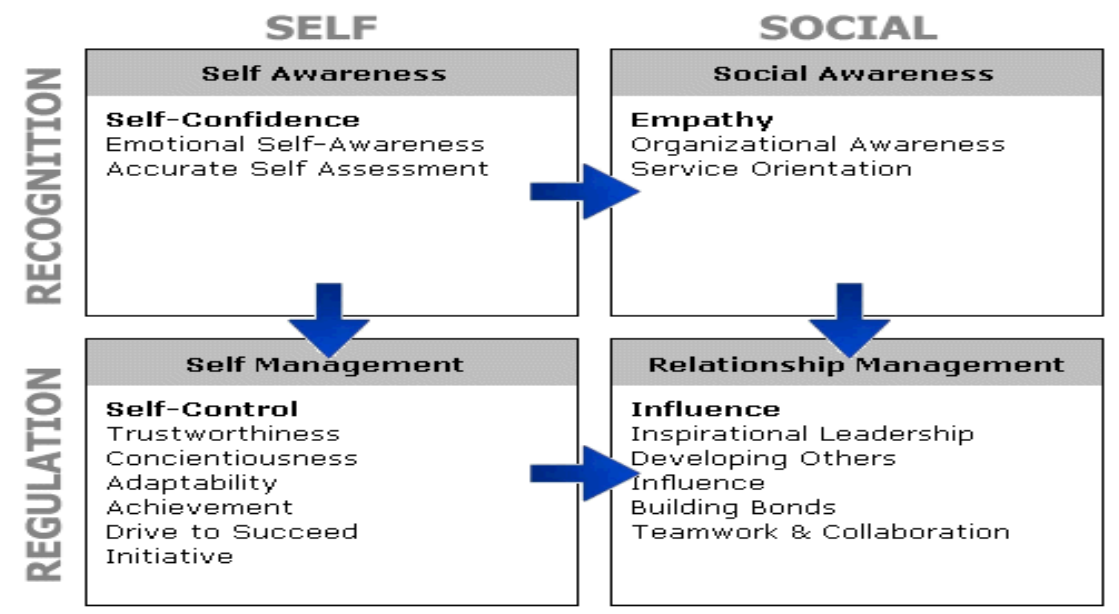

Rajah 1 : Model Kecerdasan Emosi Goleman

(Sumber : Dipetik daripada Goleman, 1995)

\section{Teori Kecerdasan Spiritual (Zohar dan Marshall, 2000)}

Dalam teori kecerdasan spiritual ini Zohar dan Marshall mendefinisikan kecerdasan spiritual sebagai kemampuan untuk mengenali aspek kerohanian dalam diri seseorang. Dalam konteks ini kecerdasan rohani (SQ) ialah kecerdasan untuk mengatasi atau memecah persoalan makna dan nilai. Kecerdasan spiritual diletakkan sebagai sumber kecerdasan yang mendasari kecerdasan intelektual, kecerdasan emosional, dan kecerdasan moral (Zohar \& Marshall, 2000). Danah Zohar, (2005) menyatakan kecerdasan spiritual merupakan kecerdasan yang membantu manusia mencari makna. Kecerdasan untuk menempatkan perilaku dan hidup dalam manusia konteks makna yang lebih luas untuk bertindak dengan lebih bermakna berbanding orang lain. Dalam erti kata lain, kecerdasan spiritual adalah asas kepada kecerdasan intelek dan kecerdasan emosi untuk berfungsi secara efektif. Kecerdasan rohani sebenarnya menggabungkan dua unsur utama iaitu unsur kerohanian spirituality dan unsur kecerdasan intelligence dalam struktur pandangan baharu (Esmaili, Zareh, \& Golverdi, 2014). 


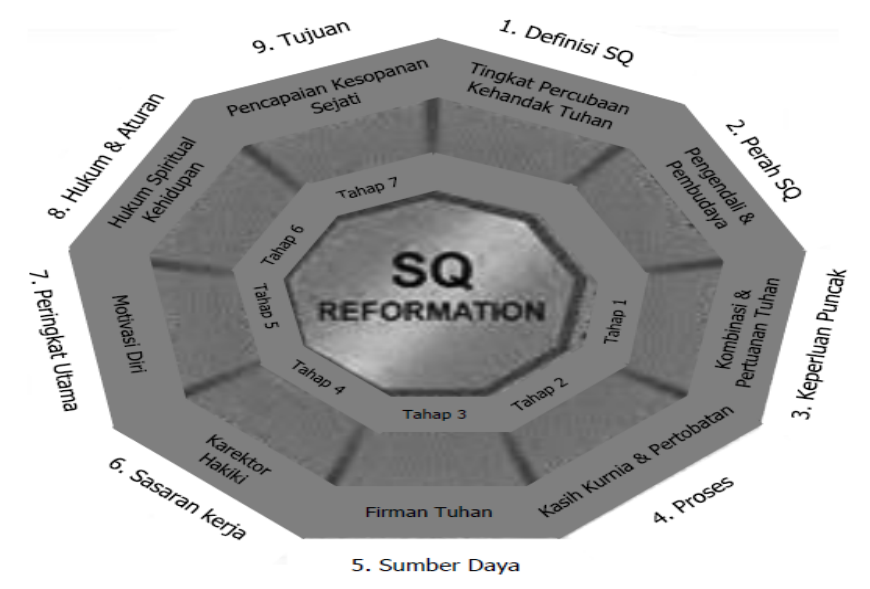

Rajah 2 : Sembilan Prinsip Pengurusan Reformasi SQ

(Sumber : Diadaptasi daripada Zohar dan Marshall, 2000)

\section{Teori Kesesuaian Persekitaran-Individu (P-E Fit)}

Penekanan terhadap Kesesuaian Persekitaran-Individu dalam penyelidikan stres adalah ciri perspektif interaktif dalam psikologi(Lewin, 1951) yang menunjukkan bahawa tingkah laku, sikap, dan kesejahteraan ditentukan secara bersama oleh persekitaran dan individu. Kesesuaian PersekitaranIndividu terhadap stres telah diformalkan dalam teori persekitaran-Individu (P-E) dan stres (Caplan, 1983;Caplan, 1987;Harrison, 1978; Caplan \& Harrison, 1993). Dalam teori P-E Fit stres yang timbul bukan dari orang atau persekitaran secara berasingan, tetapi hasil tindak balas antara persekitaran dan individu. Pengertian yang sederhana namun kuat ini dicerminkan dalam banyak teori tekanan dan kesejahteraan hidup Cummings dan Cooper, (1979) dan sebahagian besarnya bertanggungjawab terhadap kesan meluas teori P-E dalam penyelidikan stres (Edwards \& Cooper, 1990).

Dalam model ini tekanan dikatakan berlaku kerana ketidakseimbangan antara individu dengan persekitarannya. Terdapat empat buah komponen utama dalam model ini iaitu objektif persekitaran, objektif individu, subjektif persekitaran dan subjektif individu. Objektif persekitaran ialah keadaan sebenar yang wujud. Sebaliknya subjektif persekitaran merupakan keadaan persekitaran yang menjadi tanggapan terhadap persekitaran tersebut. Objektif individu pula ialah keadaan sebenar ciri-ciri peribadi seseorang individu dan subjektif individu pula merupakan tanggapan individu terhadap dirinya sendiri. Perbezaan antara subjektif persekitaran (tanggapan persekitaran individu) dan objektif persekitaran (persekitaran sebenar) akan membolehkan individu mengetahui kedudukan sebenar persekitarannya. Manakala, perbezaan antar subjektif individu (tanggapan individu terhadap dirinya) dan objektif individu (keadaan dirinya sebenar) akan membolehkan individu itu menilai dengan tepat akan keadaan sebenar dirinya.

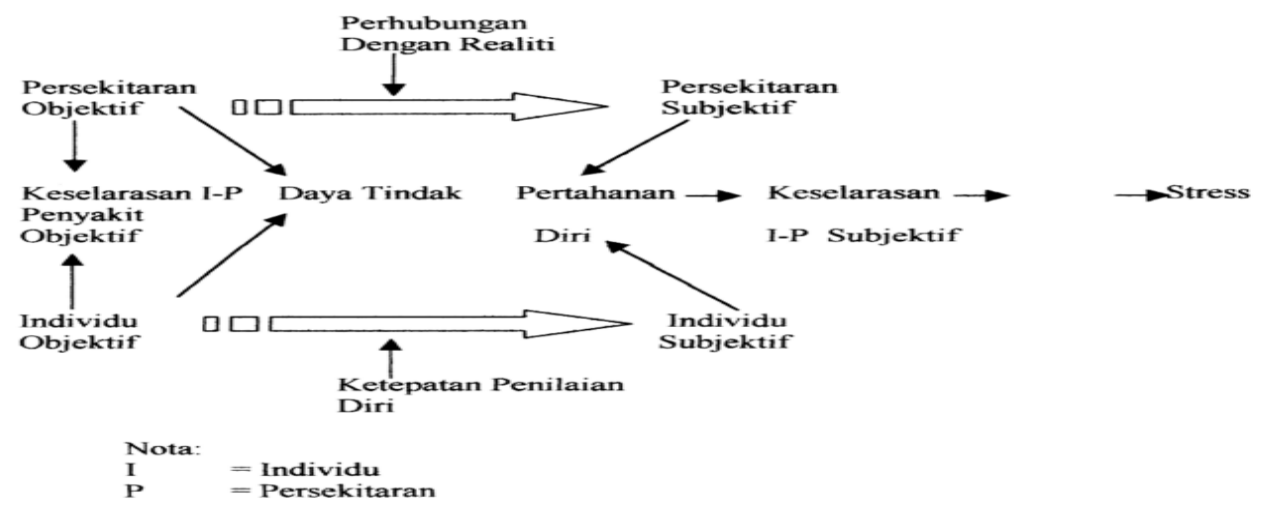

Rajah 3 : Model Kesesuaian Persekitaran-Individu (P-E) FIT (Sumber : Dipetik dari Harrison, 1978) 


\section{Teori Respon Stres General Adaptation Stress Theory}

Hans Selye merupakan seorang doktor dalam bidang kesihatan dan beliau adalah orang yang mengembangkan Model Respons Stres. Hans Selye juga adalah terkenal kerana penelitian beliau dan teori beliau yang berkaitan dengan fizikal dan kesihatan (Lyon, 2011). Pada tahun 1946 Hans Selye telah menghasilkan sebuah karya ilmiah yang bertajuk The General Adaptation Syndrome and Diseases of Adaptation. Dalam penulisan ini beliau menggunakan istilah stres untuk merujuk secara khusus pada tekanan yang datang dari luar ataupun sekeliling individu. Hans Selye memperkenalkan sebuah model stres. Model stres yang diperkenalkan Selye ialah General Adaptation Syndrome (GAS). Dalam model teroritikal ini stres diinterpretasikan sebagai respons. Definisi stres sebagai respons telah dibina dan dikembangkan oleh Hans Selye dan menurut beliau stres adalah respons yang tidak spesifik oleh badan manusia terhadap tekanan luaran (Selye, 1956; Selye, 1976).

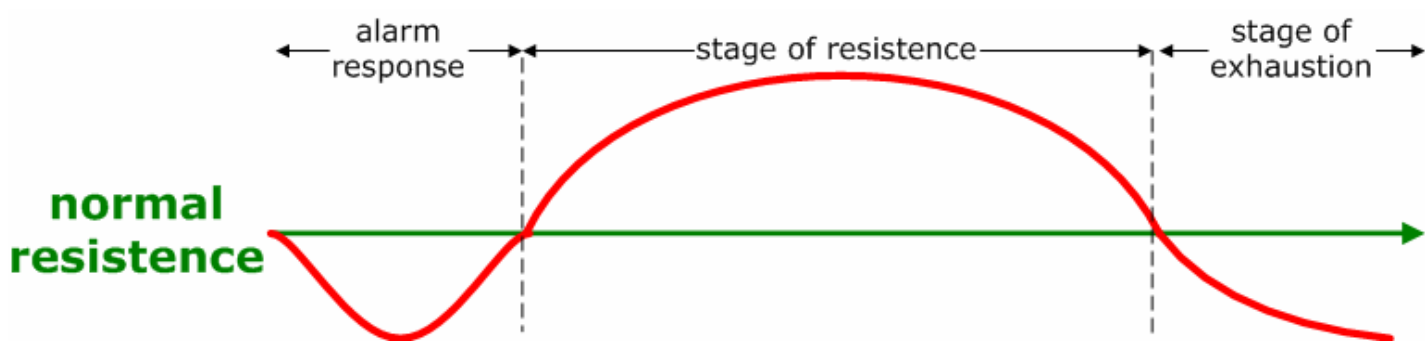

Rajah 4 : Model General Adaptation Syndrome (GAS) Sumber : Dipetik dari Hans Selye, (1956)

\section{Metod Kajian}

\section{Reka bentuk Kajian}

Kajian ini juga mengukur pengaruh kecerdasan emosi, kecerdasan spiritual dan persekitaran keluarga terhadap stres akademik murid. Dalam konteks kajian ini juga, reka bentuk konvensional menggunakan pendekatan kuantitatif melalui kaedah tinjauan menggunakan soal selidik telah diaplikasikan (Ghazali dan Sufean, 2018).

\section{Populasi dan Sampel Kajian}

Populasi dapat difahami sebagai sekumpulan set individu, objek ataupun benda kejadian yang didapati mempunyai ciri-ciri yang serupa untuk dikaji. Seramai 4052 orang murid tingkatan empat di 21 buah sekolah menengah luar bandar di bahagian Tawau negeri Sabah terpilih sebagai responden berdasarkan kehendak kajian. Daripada jumlah ini seramai 398 orang responden telah dipilih menjadi sampel kajian. Jumlah ini tidak melibatkan murid tingkatan empat yang sedang belajar di kawasan bandar, di sekolah swasta dan calon persendirian.

\section{Dapatan Kajian}

Data-data dalam penyelidikan ini dibentangkan menggunakan analisis inferens dan analisis Structure Equation Modelling (SEM)

\section{Mengenal pasti hubungan Kecerdasan Emosi, Kecerdasan Spiritual dan Persekitaran Keluarga dengan Stres Akademik}

Analisis korelasi Pearson's $r$ telah digunakan bagi menentukan hubungan variabel kecerdasan emosi, kecerdasan spiritual dan persekitaran keluarga dengan stres akademik pada aras signifikan $\mathrm{p}<0.05$. 
DOI: https://doi.org/10.47405/mjssh.v5i5.407

Jadual 1 menunjukkan hasil analisis korelasi Pearson's $\mathrm{r}$ antara variabel. Analisis menunjukkan kesemua variabel mempunyai nilai $r=0.480$ hingga 0.516 , Sig. $(2$-tailed $)=0.00(p<0.01)$. Berdasarkan analisis ini, korelasi kesemua variabel kajian menunjukkan nilai $\mathrm{p}=0.00(\mathrm{p}<0.01)$.

Jadual 1: Analisis Hubungan Variabel Kecerdasan Emosi, Kecerdasan Spiritual dan Persekitaran Keluarga dengan Stres Akademik

\begin{tabular}{|c|c|c|c|c|}
\hline \multicolumn{2}{|c|}{ Hipotesis Kajian } & $\begin{array}{l}\text { Kecerdasa } \\
\text { Emosi } \\
\mathbf{H}_{\mathbf{0 3}} \\
\end{array}$ & $\begin{array}{l}\text { Kecerdasa } \\
\text { Spiritual } \\
\mathrm{H}_{04} \\
\end{array}$ & $\begin{array}{l}\text { Persekitaran } \\
\text { Keluarga } \\
\mathbf{H}_{05}\end{array}$ \\
\hline \multirow{3}{*}{$\begin{array}{l}\text { Stres } \\
\text { Akademik }\end{array}$} & Pearson Correlation & $.489^{* *}$ & $.480^{* *}$ & $.516^{* *}$ \\
\hline & Sig. (2-tailed) & .000 & .000 & .000 \\
\hline & $\mathrm{N}$ & 398 & 398 & 398 \\
\hline
\end{tabular}

**. Correlation is significant at the 0.01 level (2-tailed).

Hasil analisis data menunjukkan variabel persekitaran keluarga mempunyai hubungan yang paling tinggi dengan variabel bersandar kajian $(r=0.516, p=0.00)$ diikuti oleh variable kecerdasan emosi $(r$ $=0.489, \mathrm{p}=0.00)$ dan variable kecerdasan spiritual iaitu $(\mathrm{r}=0.480, \mathrm{p}=0.00)$. Dapatan kajian ini membuktikan bahawa ketiga-tiga variabel tak bersandar kajian mempunyai hubungan dengan variabel bersandar kajian.

\section{Mengenal pasti Pengaruh Kecerdasan Emosi, Kecerdasan Spiritual dan Persekitaran Keluarga}

Hasil analisis dalam Jadual 2 menunjukkan korelasi kesemua tiga variabel peramal iaitu kecerdasan emosi, kecerdasan spiritual dan persekitaran keluarga dengan variabel criterion stres akademik adalah tinggi (Model 1, $\mathrm{r}=.516$, model 2, $\mathrm{r}=.613$, dan model 3, $\mathrm{r}=.663$ ). Berdasarkan analisis (model 3) kombinasi kesemua tiga variabel peramal mempunyai korelasi yang paling tinggi dengan variabel criterion stres akademik $(\mathrm{r}=.663)$. Analisis ujian regresi juga menunjukkan peratusan pengaruh kesemua tiga variabel peramal terhadap variabel criterion. Ini ditunjukkan oleh nilai kombinasi kesemua variabel peramal $\mathrm{R}^{2}=0.440, \mathrm{p}=0.00(\mathrm{p}<0.05)$ model 3 yang menyumbang penyebab kepada perubahan variabel criterion.

Jadual 2: Analisis Ujian Regresi Pelbagai

\begin{tabular}{lllll}
\hline \multicolumn{6}{c}{ Model Summary $^{\mathbf{d}}$} \\
\hline Model & R & R Square & Adjusted R Square & $\begin{array}{l}\text { Std. Error of the } \\
\text { Estimate }\end{array}$ \\
\hline 1 & $.516^{\mathrm{a}}$ & .266 & .264 & .39238 \\
2 & $.613^{\mathrm{b}}$ & .376 & .372 & .36236 \\
3 & $.663^{\mathrm{c}}$ & .440 & .436 & .34357 \\
\hline
\end{tabular}

a. Predictors: (Constant), PersekitaranKeluarga

b. Predictors: (Constant), PersekitaranKeluarga, KecerdasanSpiritual

c. Predictors: (Constant), PersekitaranKeluarga, KecerdasanSpiritual, KecerdasanEmosi

d. Dependent Variable: StresAkademik

Berdasarkan dapatan kajian ini, variabel peramal kecerdasan emosi, kecerdasan spiritual dan persekitaran keluarga dapat menerangkan 44.0 peratus daripada varians yang wujud dalam variabel criterion stres akademik. Manakala selebihnya 56.0 stres akademik murid ditentukan oleh faktor-faktor lain yang tidak dikaji dalam kajian ini. 


\section{Rumusan dan Cadangan}

Secara keseluruhannya kajian yang telah dijalankan ini berjaya mengemukakan bukti empirikal berkenaan pengaruh kecerdasan emosi, kecerdasa spiritual, persekitaran keluarga terhadap stres akademik murid sekolah menengah luar bandar bahagian Tawau Sabah. Melalui kajian ini juga kecerdasan emosi, kecerdasan spiritual dan persekitaran keluarga adalah antara elemen yang vital dalam mempengaruhi stres akademik murid sekolah menengah. Melalui hasil bacaan dapatan kajian lepas dan kesedaran tentang kepentingan pemboleh ubah dalam kajian ini menjadi pendorong utama, agar kajian ini dilaksanakan. Murid sekolah menengah harian biasa yang berada di kawasan luar bandar bahagian Tawau dipilih sebagai responden kajian kerana kumpulan ini memiliki banyak persamaan ciri antara satu sama lain. Oleh itu kajian lanjutan dalam dalam bentuk kajian pengesahan instrumen kecerdasan emosi, kecerdasan spiritual, persekitaran keluarga dan stres akademik dapat dijalankan agar wujudnya instrumen yang benar benar mampu mengukur keecrdasan emosi, kecerdasan spiritual, persekitaran keluarga dan stres akademik mengikut konteks sosio-demografi, nilai dan budaya negara kita.

\section{Kesimpulan}

Berdasarkan dapatan kajian, kecerdasan emosi, kecerdasan spiritual dan persekitaran keluarga menunjukkan hubungan, dan pengaruh terhadap stres akademik murid sekolah menengah luar bandar bahagian Tawau, Sabah. Dapatan ini perlu diberikan perhatian oleh semua pihak yang terlibat secara langsung dan tidak langsung dalam memastikan semua pihak mampu memahami stres akademik yang dialami oleh murid sekolah menengah agar mereka dapat menangani stres akademik yang dialami dengan baik. Secara keseluruhan, kejayaan institusi pendidikan di negara kita dalam melahirkan murid yang seimbang dan berjaya mendepati pelbagai situasi dipengaruhi oleh pelbagai faktor. Menerusi kajian ini, terbukti faktor kecerdasan emosi, kecerdasan spiritual dan persekitaran keluarga dan stres akademik murid adalah antara faktor yang patut diberi perhatian oleh pelbagai pihak agar objektif dan aspirasi pendidikan dapat dicapai mengikut sasaran yang telah ditetapkan.

\section{Rujukan}

Abbasi, M., Azizi, F., Goshki, E. S., Rad, M. N., \& Lakah, A. (2012). Conceptual and Operational Definition of Spiritual Health: A Psychological Study. Journal of Medical Ethics, 6, 11-44.

Abbasian, L., Abbasi, M., Gooshki, E. S., \& Memariani, Z. (2016). Survey on the Scientific Position of the Spiritual Health and its Role in Preventing from Diseases: A Preliminary Study. Journal of Medical Ethics, 4, 83-104.

Abdulghani, H., AlKanhal, A., Mahmoud, E., Ponnamperuma, G., \& Alfaris, E. (2011). Stress and its effects on medical students. A cross- sectional study at a College of Medicine in Saudi Arabia. $J$ Health Popul Nutr, 29(5), 516-522.

Amir Musarezaie, Homayoon Naji Esfahani, Tahereh Momeni-Ghaleghasemi, \& Mahin Aminoroaia. (2013). Relationship between Religious Orientation, Anxiety and Depression of Students in Isfahan University of Medical Sciences. Iranian Journal Of, 4, 509-519.

Aspelmeier, J. E., \& Kerns, K. A. (2003). Love and school: Attachment/Exploration Dynamics in College. Journal of Social and Personal Relationships, 20, 5-30.

Busari, A. O. (2012). Evaluating the Relationship between Gender, Age, Depression and Academic Performance among Adolescents. Scholarly Journal of Education, 1(1), 6-12.

Caplan, R. D. (1983). Person-environment Fit: Past, Present, and Future. In Stress Research (C. L. Coop, pp. 35-78). New York: Wiley.

Caplan, R. D. (1987). Person-environment Fit in Organizations: Theories, Facts, and Value. In Occupational Stress and Organizational eEfectiveness (A.W. Riley, pp. 103-140). New York: Praeger.

Caplan, R. D., \& Harrison, R. V. (1993). Person-environment Fit Theory: Some history, Recent Developments, and Future Directions. Journal of Social Issues, 49, 253-275. 
Malaysian Journal of Social Sciences and Humanities (MJSSH), Volume 5, Issue 5, (page 12 - 23), 2020

DOI: https://doi.org/10.47405/mjssh.v5i5.407

Chlarasinta Duri Kartika. (2015). Hubungan Antara Kecerdasan Emosi Dengan Stres Akademik Mahasiswa Fakultas Psikologi Unibersitas Muhammadiyah Suryakarta. Universiti Muhammadiyah Surakarta.

Cummings, T. G., \& Cooper, C. L. (1979). Cybernetic Framework for Studying Occupational Stress. Human Relations, 32, 395-418.

Downey, L. A., Johnston, P. J., Hansen, K., Birney, J., \& Stough, C. (2010). Investigating the Mediating Effects of Emotional Intelligence and Coping on Problem behaviors in Adolescents. Australian Journal of Psychology, 62(1), 20-29.

Edwards, J. R., \& Cooper, C. L. (1990). The Person-environment Fit Approach to Stress: Recurring Problems and Some Suggested Solutions. Journal of Organizational Behavior, (11), 293-307.

Esfahani M. (2010). Spirtual health and Comments. Medical Ethics Journal, 14(4), 41-49.

Esmaili, M., Zareh, H., \& Golverdi, M. (2014). Spiritual Intelligence: Aspects, Components and Guidelines to Promote It. International Journal of Management, Accounting and Economics, 1(2).

Essel, G., \& Owusu, P. (2017). Causes of Students' Stress, its effects on their stress management by students, A case study at Seinajoki. University of Applied Science, Finland.

Fass, M. E., \& Tubman, J. G. (2002). The Influence of Parental and Peer Attachment on College Students' Academic Achievement. Psychology in the Schools, 39, 561-573.

Forouzandeh N, Aslani Y, Mehralian H, \& Drees F. (2016). The Association between Academic Stress and Quality of Life in Students. Journal of Shahrekord University of Medical Sciences, 18(3), 17.

Forushani, N. Z., \& Besharat, M. A. (2011). Relation between emotional intelligence and perceived stress among female students. Procedia - Social and Behavioral Sciences, 30, 1109-1112. https://doi.org/10.1016/j.sbspro.2011.10.216

Garret, J. B. (2001). Gender differences in college related stress. Undergraduate Journal of Psychology, 14(11).

Ghatol, S. D. (2017). Academic Stress among Higher Secondary School Students: A Review. International Journal of Advanced Research in Education \& Technology (IJARET), 4(1), 38-41.

Ghazali Darusalam, \& Sufean Hussin. (2018). Metodologi Penyelidikan dalam Pendidikan: Amalan dan Analisis Kajian (Edisi Kedu). Penerbit Universiti Malaya, Kuala Lumpur.

Goleman, D. (1995). Emotional Intelligence: Why it can Matter more than IQ. New York: Bantam Books.

Goleman, D. (1998). Working with emotional intelligence. New York: Bantam Books.

Greven, C., Chamorro-Premuzic, T., Arteche, A., \& Furnham, A. (2008). A Hierarchical Integration of Dispositional Determinants of General Health in Students: The Big Five. Trait Emotional Intelligence and Humour Styles. Personality and Individual Differences, 22, 1562-1573.

Harrison, H. G., Koenig, J. ., Hays, A. G., Eme-Akwari, \& Pargament, K. I. (2001). The Epidemiology of Religious Coping: A Review of Recent Literature. International Review of Psychiatry, 13, 8693.

Harrison, R. V. (1978). Person-environment Fit and Job Stress. In Stress at work (C. L. Coop, pp. 175-205). New York: Wiley.

Jayanthi, P., Thirunavukarasu, M., \& Rajkumar, R. (2014). Academic Stress and Depression among Adolescents: A Cross-sectional Study. Indian Pediatrics Journal, 15, 217-219.

Kadapatti, M. G., \& Vijayalaxmi, A. H. M. (2012). "Stressors of Academic Stress-A Study of PreUniversity Students",. Indian Journal of Science Resources, 3(1), 171-175.

Kementerian Kesihatan Malaysia. (2011). Kajian Kesihatan dan Morbiditi Kebangsaan.

Kementerian Kesihatan Malaysia. (2015). Kajian Kesihatan dan Morbiditi Kebangsaan.

Kupriyanov, R., \& Zhdanov, R. (2014). The stress concept: problems and out- looks. World Journal of Medical Sciences, 11(2), 179-185. https://doi.org/http://dx.doi.org/10.5829/ idosi.wj

Leung, G. S. M., Yeung, K. C., \& Wong, D. F. K. (2010). Academic Stressors and Anxiety in Children: The Role of Paternal Support Studies. Journal of Child and Family, 19(1), 90-100. https://doi.org/10.1007/s10826-009-9288-4

Lewin, K. (1951). Field Theory in Social Science. New York: Harper.

Lyon, B. L. (2011). Stress, Coping, and Health. In Handbook of stress, coping and health: Implications for nursing research, theory, and practice (In Rice, H, pp. 3-23). USA: Sage Publication, Inc. 
Mostafa Jafari, Tahereh Sharifi Ebad, Mansour Rezaei, \& Hossein Ashtarian. (2017). Association between Spiritual Health and Depression in Students. Original Article Health, Spirituality and Medical Ethics, 4(2), 12-16. https://doi.org/10.5144/0256-4947.2012.37

Muhamad Saiful Bahri Yusoff. (2010). The Secondary School Stressor Questionnaire ( 3SQ ): Its Validity And Reliability In Identifying Stressor Among Adolescents in Secondary School. In Persidangan Pembangunan Pelajar Peringkat Kebangsaan 2010 (pp. 1-11).

Nigatu, Y. T., Bultmann, U., \& Reijneveld, S. A. (2015). The prospective association between obesity and major depression in the general population: does single or recurrent episode matter? $B M C$ Public Health Sample, 15(350). https://doi.org/http://dx.doi.org/10.1186/s12889-015- 1682-9

Rahimi, H. (2015). The Relationship between Religious Attitudes and Spiritual health with Life Satisfaction in Nursing Students of Kashan University of Medical Sciences. Medical Ethics Journal, 1(2), 9-18.

Rohana Yusof. (2004). Penyelidikan Sains Sosial. Kuala Lumpur: PTS Professional Publishing Sdn. Bhd.

Rosa, M. C., \& Preethi, C. (2012). Academic Stress and Emotional Maturity among Higher Secondary School Students of Working and Non Working Mothers. International Journal of Basic and Advanced Research, 1(3), 40-43.

Sahraian, A., Gholami, A., \& Omidvar, B. (2011). The Relationship between Religious Attitude and Happiness in Medical Students in Shiraz University of Medical Sciences. Horizon of Medical Science, 17(2), 69-75.

Saklofske, D. H., Austin, E. J., \& Minski, P. S. (2003). Factor Structure and Validity of a Trait Emotional Intelligence Measure. Personality and Individual Differences, (34), 707-721.

Seligman, M., Walker, E., \& Rosenhan, D. (2001). Abnormal Psychology (4th ed.). New York: W.W. Norton \& Company, Inc.

Selye, H. (1956). The stress of Life. New York: McGraw-Hill.

Selye, H. (1976). The Stress of Life (revised ed.). New York: McGraw Hill.

Seto Mulyadia, Wahyu Rahardjo, \& A.M Heru Basuki. (2016). The Role of Parent-child Relationship, Self-esteem, Academic Self-efficacy to Academic Stress. Procedia - Social and Behavioral Sciences, 217, 603-608. https://doi.org/10.1016/j.sbspro.2016.02.063

Shaikh, B. T., Kahloon, A., Kazmi, M., Khalid, H., Nawaz, K., Khan, N. A., \& Khan, S. (2004). Students, stress and coping strategies: A case of Pakistani Medical School. Education for Health, 17(3), 346-353. https://doi.org/10.1080/13576280400002585

Slaski, M., \& Cartwright, S. (2002). Health, Performance and Emotional Intelligence: An Exploratory Study of Retail Managers. Stress and Health, 18, 63-68.

Tan, Y. M., Goh, K. L., Muhidayah, R., Ooi, C. L., \& Salem, O. (2003). Prevalence of irritable bowel syndrome in young adult Malaysians: A survey among medical students. Journal of Gastroenterol Hepatol, (18), 1412-1416.

Waghachavare, V. B., Chavan, V. M., Dhumale, G. B., \& Gore, A. D. (2013). A Cross-Sectional Study of Stress among Junior College Students in a Rural Area of Sangli District of Maharashtra. Innovative Journal of Medical and Health Science, (November-December), 294-297.

World Health Organization. (2002). "World Health Report 2002: Reducing Risks, Promoting Healthy Life. "Retrieved from https://apps.who.int/iris/bitstream/handle/10665/42510/WHR 2002.pdf?sequence=1

World Health Organization. (2009). International Statistical Classification of Diseases and Related Health Problems.Retrieved from https://books.google.com.my/books?hl=en\&lr=\&id=0byXrYpnFBoC\&oi=fnd\&pg=PR5\&dq=wor ld+Health+Organization.+(2009). + International+Statistical+Classification+of+Diseases + and + Rel ated + Health + Problems.\&ots $=$ GUiljsh30A\&sig $=8$ Uigedki709nUa-

QdwGZjwkHxYE\#v $=$ onepage \&q\& $\mathrm{f}=$ false

Zainudin Awang, Lim Siew Hui, \& Nur Fairuza Syahira Zainudin. (2018). Pendekatan Mudah SEM (structural Equation Modelling). MPWS Rich Publication.

Zavala, A. M., \& Lopez, I. (2012). Adolescents at Risks: What is the Role of Emotional Intelligence? Behaviour Psychology, 21, 159-175.

Zohar, D., \& Marshall, I. (2000). SQ: Spiritual Intelligence, the Ultimate Intelligence. New York: Bloombury. 
Malaysian Journal of Social Sciences and Humanities (MJSSH), Volume 5, Issue 5, (page 12 - 23), 2020

DOI: https://doi.org/10.47405/mjssh.v5i5.407

Zohar, Danah. (2005). Spiritually Intelligent Leadership. Leader to Leader, 2005(38), 45-52. https://doi.org/10.1002/lt1.153 